\title{
Applicability study of permeable pavements in Dubai
}

\author{
F. Kfoury, P. Kianmehr \& H. El-Hassan \\ Department of Civil Engineering, American University in Dubai, UAE
}

\begin{abstract}
It is estimated that during the year 2013 Dubai expended nearly 450 million USD on rainwater flooding, an incident that is reported on an average of four times per year. In the year 2020, this figure is estimated to increase to nearly 750 million USD, as Dubai GDP increases. In addition to financial losses, rainwater flooding incurs life fatalities, car accidents, municipal burdens, and municipal disturbances. The inadequacy of run-off drainage systems in impermeable paved areas is the most profound reason for the occurrences of rainwater flooding in Dubai. National as well as international organizations such as ESTIDAMA and the United States Green Buildings Council (USGBC) advocate using permeable landscaping materials to decrease run-off in landscapes near buildings. While a substantial national effort has been made in this regard, very minimal action is being taken to reduce run-off from paved roadways. Paved roadways occupy the majority of impermeable areas in Dubai; hence, decreasing its associated rainwater run-off would significantly lessen the occurrences of rainwater flooding. Permeable pavements have great potential in eliminating rainwater overflow of roadways without the need of independent drainage systems. The aim of this research is to study the essential parameters that would determine the applicability of permeable pavements in Dubai.

Keywords: concrete pavement, sustainabiity, runoff, stormwater collection, sandy soil, dust.
\end{abstract}

\section{Introduction}

Many worldwide environmental agencies and organizations, such the U.S. Environmental Protection Agency (EPA), and the U.S. Green Buildings Council (USGBC), recommend permeable pavements as green alternatives for the current paving systems. The EPA describes four main advantages of permeable 
pavements. In comparison to traditional dense pavements, permeable pavements allow the natural treatment of water due to increased retention time before its discharge into the environment, require less curbing and storm water collection systems, improve driving safety by increasing the pavement's skid resistance and replenish ground water aquifers beneath the pavement [1]. Other advantages include reducing glare on road surfaces, reducing the tire-pavement noise, preserving natural ecosystems, and reducing cost when compared to traditional pavements [2]. Perhaps, the main advantage of permeable pavements is decreasing the amount of rain water run-off; thus, reducing the need for storm water collection systems. Such an advantage is especially valuable for places encountering ponding problems in roadway drainage systems, such as Dubai. On average, heavy rain in Dubai occurs four times per year, as per Dubai precipitation charts from 2010-2012 [3]. Such incidents cause severe traffic disturbances, road flooding, car accidents, economic losses, and life causalities [4]. From an economic perspective, it is estimated that these events incurred more than 450 million USD of losses on Dubai's economy during the year of 2012 and would incur more than 750 million USD during the year of 2020. The estimation was computed as per Equation (1). Within a given year, $i$, the total loss (in USD) incurred on Dubai Municipality due to rain flooding, $\Delta \operatorname{Loss}_{i}$, is the product of its GDP in that year, the service sector contribution, $\mathrm{S}$, and the degree of services sector halt, $\mathrm{k}$.

$$
\Delta \operatorname{Loss}_{i}=\frac{G D P_{i}}{250 \text { days }} \times 4 \text { days } \times S \times k_{i}
$$

The following assumptions were considered in the calculation of losses:

1. A rainy day would only halt 50 percent of the services sector of the economy, which incorporates $38.8 \%$ of Dubai GDP [5].

2. The heavy rain occurred during working days (250 days per year).

3. Dubai GDP during the year of 2012 is 144.5 billion USD and 241 billion USD in the year of 2020, as per the Institute of International Finance [6].

4. The service sector contribution to Dubai GDP is taken as 0.388 .

5. The degree of services sector halt due to rain flooding is assumed to be 0.5 .

It should be noted that the estimated values are well on the conservative side as they exclude the cost of the physical damages caused by roadways flooding, life fatalities due to increase in traffic accidents rate, and municipal expenses for pumping water out of ponded areas.

\section{Research significance}

The purpose of this study is to investigate the applicability of implementing selfdraining permeable pavements in Dubai. Through experiments and simulations, major concerns that might hinder the implementation of permeable pavements in Dubai were examined. The parameters under investigation included fine dust accumulation intensity, fine dust grain size distribution, sub-grade permeability, sub-grade clogging potential, permeability of locally batched porous concrete, clogging potential, and compressive strength. 


\section{Experimental investigations}

\subsection{Permeable pavements}

Typically, a permeable pavement has three components: the permeable surface course, the base course, and the subgrade. The surface course is the pavement layer that is directly exposed to traffic loads. This layer determines the surface quality characteristics of the pavement such as travel quality, reflectivity, and resistance to traffic abrasion [7].

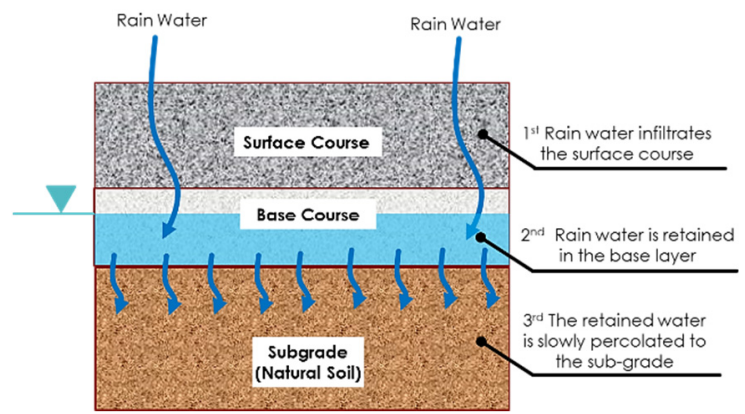

Figure 1: Typical self-draining permeable components.

The base course is the layer that comes directly underneath the surface course. From a structural perspective, this layer transfers the load from the surface course to a larger area of the subgrade. Hence, it decreases the stress imposed on the subgrade due to traffic loads. From a hydraulics perspective, the base course is a layer highly permeable to water that acts as a temporary retention reservoir for water that infiltrated from the surface course. It is the difference in permeability of the subgrade compared to the permeability of the surface course and the maximum rain intensity that determines the thickness of this layer. The subgrade is typically the natural soil layer on which the pavement will be constructed. The permeability of the subgrade drastically alters the permeable pavement design from a hydraulics perspective. Non-cohesive subgrades such as sand and gravel are suitable for self-draining permeable pavements. However, pavements constructed on cohesive subgrades such as clay would require drainage mechanisms for water accumulating in the base course. Given the sandy nature in Dubai, this research focuses on self-draining permeable pavements. Figure 1 shows a typical self-draining permeable pavement assembly and its drainage mechanism.

\subsection{Porous asphalt versus porous concrete surface course}

From an economic perspective, concrete pavements have a higher initial cost than asphaltic pavements; however, on the long run concrete pavements maintenance costs are much lower than that of asphaltic pavements. Typically, concrete pavements would cost less if both short and long term costs were taken into consideration [7]. From a service life perspective, the exposure of porous 
asphalt to rain water could cause the bituminous asphaltic binder to wear off from the surface and seep through the surface course pores; eventually, causing clogging [7]. On the other hand, porous concrete pavement disadvantages include high susceptibility to freeze-thaw cycles and low flexural strength. While the first disadvantage is not applicable to Dubai due to the absence of freezing and thawing cycles, the second disadvantage can be mitigated utilizing synthetic fibers [8]. Furthermore, the light color of concrete, with an albedo of 0.55 , compared to the relatively darker color of asphalt, with an albedo of 0.04 , decreases the heat island effect of pavements [7]. Based on the performance comparison, it can be concluded that porous concrete pavements would outperform porous asphaltic pavements in Dubai in particular. Accordingly, this research would investigate porous concrete surface course.

\subsection{Dubai rain fall intensity}

Limited literature has been found on the rain fall intensity in Dubai as function of the rainfall duration. Only rain fall intensity literature about Wadi Tawiyean [9], shown in Figure 2, has been found. For the purpose of this study, it has been assumed that Wadi Tawiyean rain fall statistics are representative of Dubai as well. The figures show that the maximum rainfall intensity drastically varies from $10 \mathrm{~mm} / \mathrm{hr}$ per 2 years to $85 \mathrm{~mm} / \mathrm{hr}$ per 250 years [9].

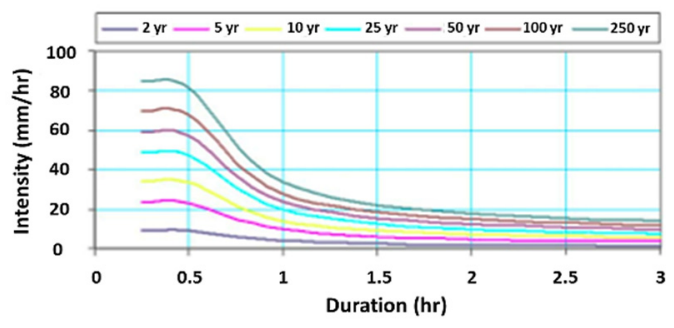

Figure 2: Wadi Tawiyean, UAE rain intensity [9].

\subsection{Local fine dust and sand accumulation intensity}

The clogging of porous pavement due to fine dust or sand is a major concern in the service life of porous pavements [10]. Fine dust may also clog the surface course or the natural permeable soil. Hence, statistics about sand and fine dust accumulation intensity per unit area is of great importance for studying the service life of permeable pavements. A research by Hamza et al. [11] studied sand accumulation at five coastal areas in the United Arab Emirates during sandy storms, mainly Jebel Al-Dhanna, Abu Dhabi, Um Al-Quwain, Dibba and Fujirah. The study showed that dust deposition during sunny sand storms days averaged $9.34 \mathrm{~g} / \mathrm{m}^{2}$.day ${ }^{-1}$ and during rainy sand storms averaged $3.53 \mathrm{~g} / \mathrm{m}^{2}$.day ${ }^{-1}$. The peak dust accumulation value for sunny days $\left(21.31 \mathrm{~g} / \mathrm{m}^{2}\right.$.day $\left.{ }^{-1}\right)$ is going to be utilized in this research. Extrapolating the results per year based on the peak number of sand storms per year, yields to a peak sand accumulation intensity of $645 \mathrm{~g} / \mathrm{m}^{2} /$ year assuming sand storm lasts the whole year. Due to the lack 
of literature about fine dust accumulation in Dubai, an experiment has been performed at the American University in Dubai, located in the western side of Dubai, over the course of a year to measure fine dust accumulation intensity. The experiment measured fine dust accumulation in an elevated $19.5 \mathrm{~m}^{2}$ balcony. The results had shown an accumulation of $25 \mathrm{~g} / \mathrm{m}^{2}$.day ${ }^{-1}$.

\subsection{Base characteristics}

As mentioned earlier, the base in a permeable pavement serves two purposes, a structural purpose as well as a hydraulics purpose. Based on those requirements, a base in a permeable pavement should have enough strength to support the surface course at the same time enough permeability to fulfill its function as a temporary water retention reservoir. The strength of any pavement component is characterized by the California Bearing Ratio (CBR). The CBR of the base as recommended by [7] should typically vary from $50 \%$ to $60 \%$. Such percentages would structurally classify the base as good and excellent respectively. It should be noted that it is possible to have bases with a lower CBRs, however, such CBRs would structurally classify the base as poor stability base. In these cases, a thicker pavement would be required. The relationship between the pavement thickness and the base thickness will be governed by the AASHTO method for pavement design. From a hydraulics perspective, the volume of the base layer should be adequate for retaining peak rain water accumulation per storm. Based on the structural and hydraulic requirements of the CBR, this study recommends the usage of poorly graded gravel, with "A-1-A" AASHTO classification. Such base type has both, a relatively high permeability, $0.005 \mathrm{~cm} / \mathrm{s}$ on average, and an acceptable strength, up to $60 \%$ CBR [12].

\subsection{Porous concrete mix design philosophy}

On average, typical porous concrete mixes contain about $20 \%$ water-permeable voids [13]. Porous concrete has exactly the same components of dense concrete, mainly course aggregates, fine aggregates, and cementitious paste, yet with different proportioning. Course aggregates are the main element of porous concrete mixes that highly contributes to the mix porosity. In order to obtain high levels of porosity, course aggregates are typically gap-graded. Porosity of gap graded aggregates used in porous concrete mixes revolves around $40 \%$. Little or no fine aggregates are usually added to the mix. In certain cases where the susceptibility of freeze-thaw is of a major concern, around $5 \%$ to $7 \%$ (by volume) of fine aggregates is added to the mix [14]. Beeldens [15] cites other benefits for adding relatively small amounts of fine aggregates to the porous concrete mixes such as increase in durability and strength. The third component of a porous concrete mix is the cementitious paste. The cementitious paste in a porous concrete mix is analogous to the bituminous binder in an asphaltic mix. It is the volume of added cementitious paste that determines porosity of the porous concrete mix.

Porous concrete mix design philosophy is based on three main assumptions. First, the volume of the mix is determined by the volume of course aggregates. In 
the absence of fine aggregates, the volume of the mix is assumed to be equal to $99 \%$ that of the aggregates volume. Second, the added cementitious paste uniformly occupies the voids between the course aggregates. Third, the target porosity is determined by subtracting the cementitious paste volume (including the volume of fine aggregates) from the initial voids of the gap graded course aggregates then dividing it by the total mix volume. Perhaps a technically valid term for describing porous concrete would be "cemented aggregates". Figure 3 visualizes the later three assumptions.

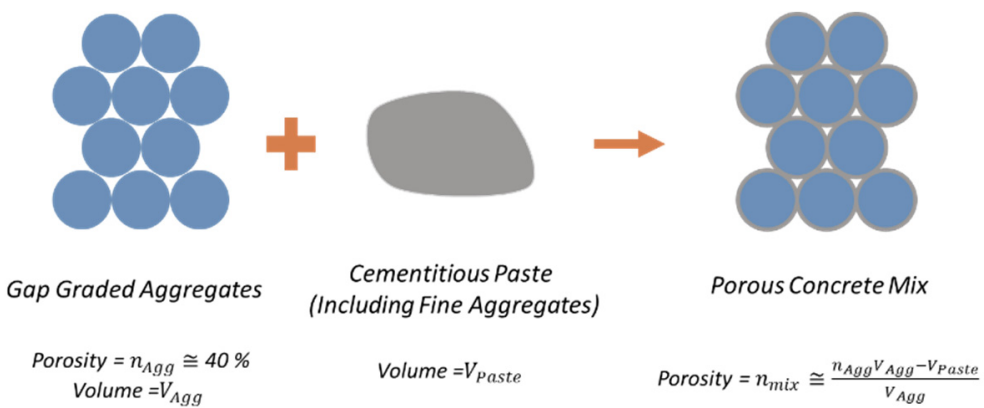

Figure 3: Visualization of porous concrete mix design philosophy.

\subsection{Porous concrete pavement structural design philosophy}

Even though porous concrete pavements were being used since the early $80 \mathrm{~s}$, there is no standardized design method for determining the structural design of such pavements. It is however assumed in most reviewed literature that porous concrete behaves as a rigid pavement. Accordingly, two methods would be valid for porous concrete pavement structural design, the 1993 AASHTO method and PCA 1984 method. In his research about the structural design of porous concrete pavements, [16] investigates the applicability of each of the two methods to porous concrete pavements. The results showed the validity of categorizing porous concrete pavements as rigid pavements; in addition, the results showed that the AASHTO 1993 method performs better than the PCA 1984 method in designing porous concrete pavements. The literature shows that the ASHTO 1993 method under designed porous concrete pavements $14 \%$ of the time, as opposed to $29 \%$ of the time in the case of the PCA 1984 method [16]. It should be noted that the 14\% AASHTO 1993 underestimation rate fits well within the $85 \%$ chosen reliability index mentioned in the literature [16]. Hence, this study recommends the use the AASHTO 1993 method for the structural design of porous concrete.

\section{Experimental simulations}

\subsection{Dubai fine dust analysis (ASTM D4318 and ASTM D422-63)}

The Atterberg limits test was performed, as per ASTM D4318, on the dust sample to evaluate its liquid and plastic limits as part of identifying the obtained 
dust sample type. The test results showed the dust sample is non-plastic with a liquid limit of $27 \%$. Sieve analysis was also performed on the sample as per ASTM D422-63 and showed that typical Dubai fine dust type is low plasticity silt. Figure 4 shows the typical grain size distribution of Dubai fine dust.

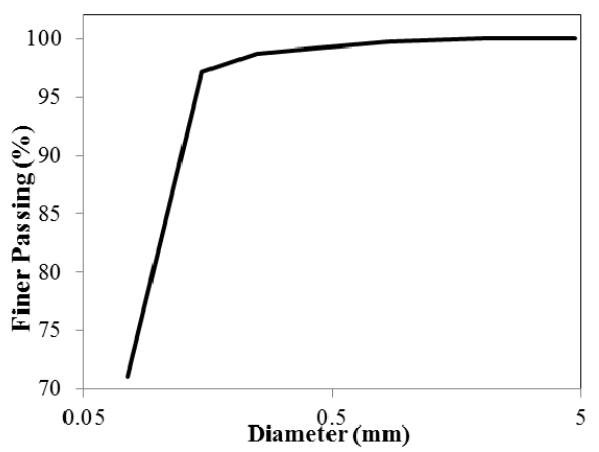

Figure 4: Grain size distribution of typical Dubai fine dust.

\subsection{Typical Dubai sand standard proctor test (ASTM D698)}

The preparation for pavement construction typically involves the compaction of the subgrade to ensure its stability. The standard proctor test has been performed on random Dubai sand samples as an attempt to determine the optimum moisture content and the maximum achievable dry unit weight given the standard proctor compaction effort. The maximum standard unit weight if the soil under study was found to be $19.9 \mathrm{kN} / \mathrm{m}^{3}$ with an optimum moisture content of $12 \%$. The constructed compaction curve is shown in Figure 5.

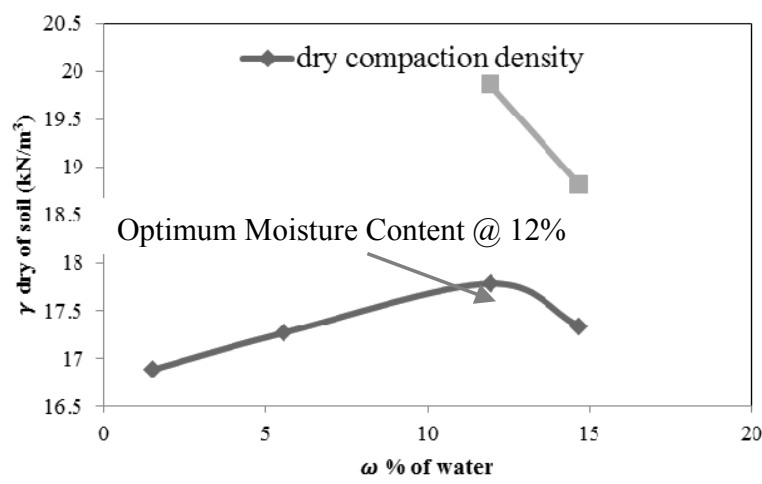

Figure 5: Compaction curve of typical Dubai sand.

\subsection{Typical Dubai sand permeability test}

The purpose of the soil permeability test is to measure the permeability of the soil in the land under consideration. The permeability test also investigates the clogging potential of local sand due to fine dust exposure. Hence, it aims to 
establish a relationship between local sand permeability and dust exposure in grams. The dust exposure in grams will be correlated to dust exposure duration in years according to the reviewed literature. In order to simulate the effect of dust accumulation on top of the sand layer, a controlled volume of dusty water with a certain concentration of dust was incrementally added to a sand sample compacted to $90 \%$ standard proctor unit weight. The entire setup was performed in the ASTM falling head permeability apparatus which allowed the permeability measurement. Equation 2 used to determines the coefficient of permeability in the sand clogging test, utilizing Darcy's law.

$$
\mathrm{k}=\frac{\mathrm{L}}{\mathrm{t}} \ln \left(\frac{\mathrm{L}+\mathrm{h}_{1}}{\mathrm{~L}}\right)
$$

where

- $\quad k$ is the coefficient of permeability of the tested sample $(\mathrm{cm} / \mathrm{s})$

- $h_{1}$ is the initial height of dusty water $(\mathrm{cm})$

- $L$ is the length of the sand sample $(\mathrm{cm})$

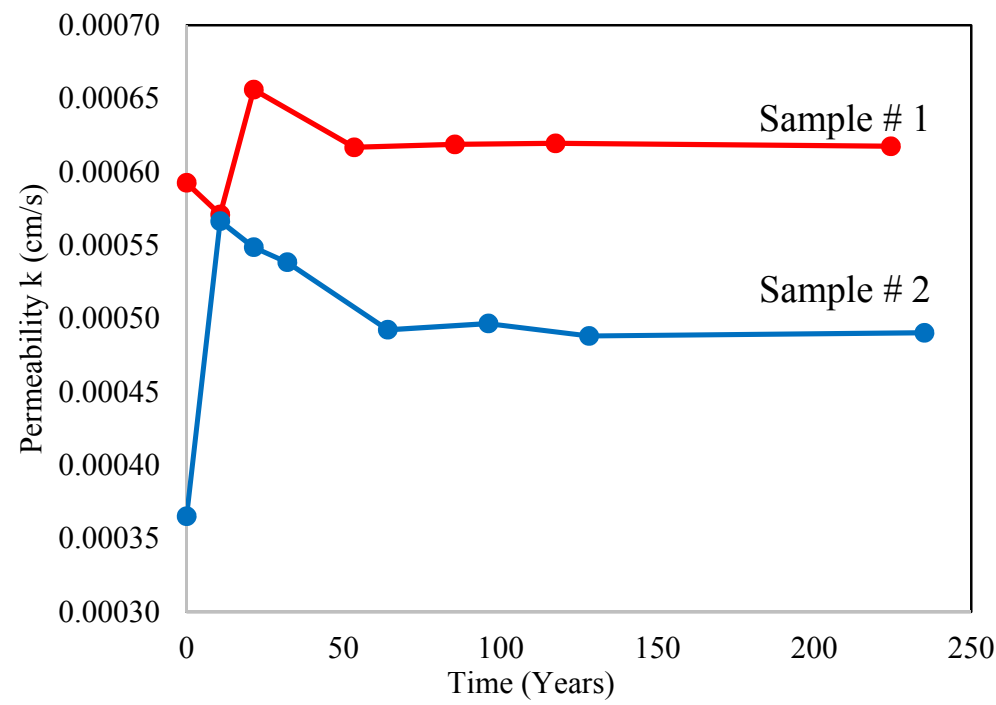

Figure 6: Sand permeability $(\mathrm{cm} / \mathrm{s})$ versus dust exposure (years).

In order to ensure that the test results are reproducible the sand clogging test was performed on two different samples both taken from undeveloped lands within partially developed area in Al Barsha in Dubai. The results of the performed sand clogging tests are plotted in Figure 6. The results showed that the dust clogging potential of the typical Dubai soil is very minimal and is not an obstacle for permeable pavements implementation. 


\subsection{Porous concrete trial mixes}

In total, four trial mix designs were casted in standard $150 \mathrm{~mm} \times 150 \mathrm{~mm} \times$ $150 \mathrm{~mm}$ cubes. Table 1 summarizes the composition and the target porosity of every mix design grouped chronologically as per their casting time. Type A mix was the first casted mix with almost $30 \%$ target porosity.

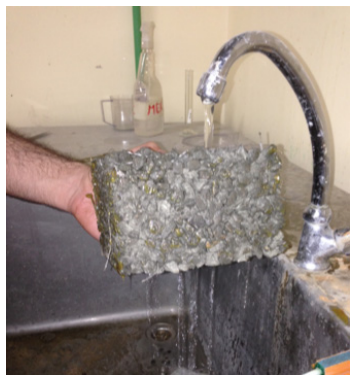

Figure 7: $\quad$ Significant permeability of Type-A casted cube.

Table 1: $\quad$ Mix designs.

\begin{tabular}{|c|c|c|c|c|c|c|c|c|}
\hline \multirow[t]{2}{*}{ Sample } & \multicolumn{3}{|c|}{ Mixture proportions (\%) } & \multirow{2}{*}{$\begin{array}{l}\text { Target } \\
\text { porosity } \\
(\%)\end{array}$} & \multicolumn{3}{|c|}{$\begin{array}{l}\text { Aggregate } \\
\text { composition (\%) }\end{array}$} & \multirow[b]{2}{*}{ Additives } \\
\hline & Aggregates & OPC & Water & & $10 \mathrm{~mm}$ & $5 \mathrm{~mm}$ & $3 \mathrm{~mm}$ & \\
\hline A-1 & 82.10 & 13.50 & 4.40 & 29 & 50 & 50 & 0 & $\mathrm{n} / \mathrm{a}$ \\
\hline A-2 & 82.10 & 13.50 & 4.40 & 29 & 50 & 50 & 0 & $3 \%$ fibers \\
\hline B-1 & 67.80 & 24.80 & 7.40 & 7 & 0 & 50 & 50 & $\mathrm{n} / \mathrm{a}$ \\
\hline B-2 & 67.80 & 24.80 & 7.40 & 7 & 0 & 50 & 50 & $3 \%$ fibers \\
\hline $\mathrm{C}-1$ & 69.10 & 24.70 & 6.20 & 12 & 0 & 50 & 50 & $\mathrm{n} / \mathrm{a}$ \\
\hline D-1 & 67.70 & 24.30 & 8.00 & 12 & 0 & 100 & 0 & $\mathrm{FA}^{\mathrm{a}}+\mathrm{SP}^{\mathrm{b}}$ \\
\hline
\end{tabular}

${ }^{\mathrm{a}}$ Fly Ash, b Super Plasticizer.

In terms of permeability, Type A mix (shown in Figure 7), was a great success. However, the mix had a very rough texture and a significant aggregates raveling tendency. In an attempt to get a smoother surface, another mix, type B, was casted with smaller aggregates and a target porosity of 7\%. Type B mix had a relatively much smoother surface than Type A mix, however, it was not permeable enough to allow water to seep all the way through the cube. It should be noted that Type B mix allows water to drain only from the sides of the cube at depth roughly equal to half that of the cube. Such permeability is considered as a zero permeability for the purpose of constructing porous concrete pavements. After casting Type A and Type B mixes, the purpose shifted to achieving a compromise mix that would have a smooth texture at the same an acceptable permeability. The aim of the trial mix designs was to achieve a porous concrete mix with acceptable strength, permeability, and surface quality. Out of the four trial mixes, the $12 \%$ porosity double graded mix satisfied the three set criteria. It should be noted that the $12 \%$ porosity double graded mix had a 28 day compressive strength (ASTM C109) of $22 \mathrm{MPa}$ and flexural strength (BS EN 
12390-5:2009) of 3.3 MPa. The typical minimum acceptable concrete strength for roadways is $21 \mathrm{MPa}$ [17]; hence, the obtained strength was deemed acceptable. The study recommends further investigation of the possibility of achieving a higher strength porous concrete mix given the locally available materials in future studies.

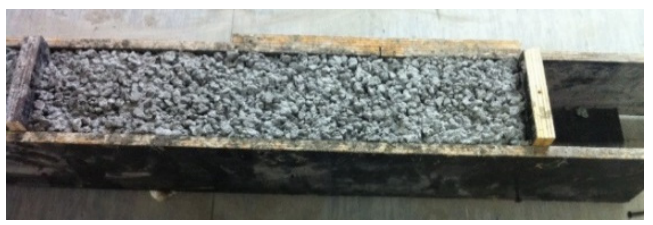

Figure 8: Casted $10 \mathrm{~cm} \mathrm{x} 10 \mathrm{~cm}$ x $50 \mathrm{~cm}$ Porous concrete beam.

\subsection{Porous concrete permeability test}

The permeability test aims to measure the coefficient of permeability of porous concrete. The concrete permeability test also aims to establish a relationship between the permeability porous concrete and the dust exposure duration. ACI Committee 522 recommends the falling head permeability test for measuring porous concrete permeability. For the purpose of this project a customized version of the falling head permeability test was derived. As per Darcy's law, the coefficient of permeability is given by Equation (3).

$$
\mathrm{k}=\frac{\mathrm{A}_{\mathrm{p}} \mathrm{L}}{\mathrm{A}_{\mathrm{c}} \mathrm{t}} \ln \left(\frac{\mathrm{L}+\mathrm{h}_{1}}{\mathrm{~L}}\right)
$$

where

- $\quad k$ is the coefficient of permeability of the tested sample $(\mathrm{cm} / \mathrm{s})$

- $A_{p}$ and $A_{c}$ are the PVC pipe and concrete cube areas respectively $\left(\mathrm{cm}^{2}\right)$

- $h_{1}$ is the initial height of water in the PVC pipe $(\mathrm{cm})$

- $\quad L$ is the length of the concrete cube $(\mathrm{cm})$.

Figure 9 shows the utilized permeability test apparatus. The concrete permeability test was performed on the $12 \%$ porosity sample. The clogging materials used were sand and dust. Multiple cycles of adding clogging material to the surface of wetted concrete followed by adding a volume of water were performed. For every cycle the time required for the water to drain was recorded. Those cycles were repeated until concrete became practically impermeable. When a state of very low permeability was reached (less than $10 \%$ of initial permeability), concrete was flushed with a water hose (as shown in Figure 10). After flushing the surface of the concrete sample, the permeability of concrete was measured. The sample was then dried for 24 hours after which the permeability of the sample was measured. After measuring the permeability of the sample in a dry condition, the permeability of the sample was measured again in a wet condition.

The concrete clogging test showed that without any maintenance, it would take the casted porous concrete mix 13 years to clog due to sand and 38 years to 

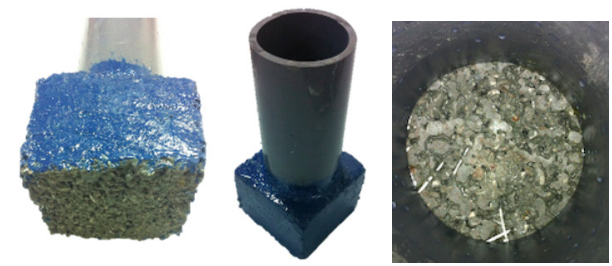

Figure 9: Permeability test apparatus.

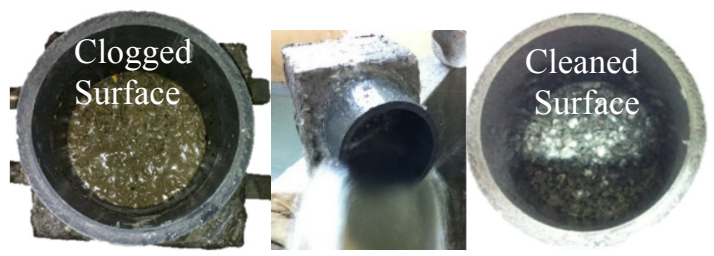

Figure 10: Flushing mechanism.

clog due to fine dust accumulation. The results also showed that flushing the surface of clogged concrete entirely recover lost permeability due to sand exposure and partially recovers lost permeability due to fine dust exposure. The results are promising and indicate that porous concrete pavements can be implemented with minimal maintenance. After performing concrete clogging test on a concrete sample, the sample was fractured at a section in an attempt to identify dust penetration depth. The fracture surface successfully identified the clogging locations of the concrete sample. It has been shown that over a simulated period of 38 years of dust exposure, fine dust penetration would vary from 1 to $2 \mathrm{~cm}$.

\section{Conclusion}

This study has evaluated the applicability of permeable pavements in Dubai as a solution for roadways ponding problem due to occasional rainwater. The results showed that Dubai fine dust is composed of low plasticity silt. The clogging potential of typical Dubai sand due to fine dust exposure is minimal and is not an obstacle for permeable pavements implementation. The long term permeability of Dubai Sand was measured be $0.0005 \mathrm{~cm} / \mathrm{s}$. Porous concrete with acceptable permeability $(0.005 \mathrm{~cm} / \mathrm{s})$ flexural strength $(3.2 \mathrm{MPa})$ and compressive strength (22 $\mathrm{MPa}$ ) can be batched given locally available materials. The clogging potential of porous concrete due to sand and fine dust exposure is acceptable. Further investigations are conducted to develop better concrete permeable pavement.

\section{Acknowledgements}

The authors of this paper would like to thank Omar Swaid, and Ahmad Kaddoura and everyone who supported this research. 


\section{References}

[1] Lee, M., Huang, Y., Chang, T., and Pao, C., Experimental Study of Pervious Concrete Pavement. Emerging Technologies for Material, Design, Rehabilitation, and Inspection of Roadway Pavements, pp. 93-99, 2011.

[2] ACI-522-Committee, "Report on Pervious Concrete," American Concrete Institute, Michigan, 2010.

[3] WeatherSpark, "Historical Weather For 2012 in Dubai, United Arab Emirates," [Online]. Available: http://weatherspark.com/history/32855/ 2012/Dubai-United-Arab-Emirates.

[4] Carroll L., "Rain and Wind Cause Havoc on Emirates Road," 7 January 2014. [Online]. Available: http://www.thenational.ae/uae/environment/ one-dead-amid-flooding-and-traffic-chaos-after-heavy-rains-in-uae.

[5] Central Intelligence Agency, "UAE Factbook," 28 Januaru 2014. Available: https://www.cia.gov/library/publications/the-world-factbook/ geos/ae.html.

[6] George Abed, "Economic Research, UAE," 31 October 2013. [Online]. Available: http://www.iif.com/emr/mena/UAE/.

[7] Ferguson B. K., Porous Pavements, New York: Taylor and Francis, 2005.

[8] Huang B. Wu H., Shu X., Burdette E. G., "Laboratory evaluation of permeability and strength of polymer-modified pervious concrete," Construction and Building Materials, pp. 818-823, 2010.

[9] Sherif, M., Akram, S., and Shetty, A., "Rainfall Analysis for Northern Wadis of United Arab Emirates," Journal of Hydrologic Engineering, pp. 535-544, 2009.

[10] Coughlin, J., Campbell, C., and Mays, D. "Infiltration and Clogging by Sand and Clay in a Pervious Concrete Pavement System," Journal of Hydrologic Engineering Vol. 17, pp. 68-73, 2012.

[11] Hamza W., Enan M. A., Al-Hassini H.,Stuut J. B., de-Beer D. "Dust storms over the Arabian Gulf: a possible indicator of climate changes consequences," Aquatic Ecosystem Health \& Management, pp. 260-268, 2011.

[12] Delate N., Concrete Pavement Design, Construction, and Performance, New York: Taylor \& Francis, 2008.

[13] Kevern J. T., "Mixture Proportioning Considerations for Improved FreezeThaw Durability of Pervious Concrete," ISCORD, pp. 571-481, 2013.

[14] Kevern, J. T., Schaefer, V. R., Wang, K., Suleiman, M. T., "Pervious Concrete Mixture Proportions for Improved Freeze-Thaw Durability," ASTM Int., Vol. 5, No. 2, 2008.

[15] Beeldens A., "Behavior of Porous PCC Under Freeze-Thaw Cycling," in Tenth International Congress on Polymers in Concrete, Honolulu, 2001.

[16] Goede W. G., "Pervious Concrete: investigation into structural performance and evaluation of the applicability of existing thickness design methods," Washington State University, USA 2009.

[17] ACI-330-Committee, "Guide for Design and Construction of Concrete Parking Lots," American Concrete Institute, 2001. 